\title{
Approaching EdD Program Redesign as a Problem of Practice
}

\author{
Lesley F Leach, PhD \\ Associate Dean of Research and Innovation \\ Tarleton State University \\ leach@tarleton.edu \\ Juanita M Reyes \\ Assistant Professor \\ Tarleton State University \\ jreyes@tarleton.edu \\ Credence Baker \\ Associate Professor \& Associate Graduate Dean \\ Tarleton State University \\ cbaker@tarleton.edu \\ Ryan Glaman \\ Assistant Professor, Doctoral Program Coordinator \\ Tarleton State University \\ glaman@tarleton.edu \\ Jordan M Barkley \\ Associate Provost \& Associate VP for Academic Administration \\ Tarleton State University \\ jbarkley@tarleton.edu \\ Don M Beach \\ Regents Professor \\ Tarleton State University \\ beach@tarleton.edu \\ J Russell Higham \\ Associate Professor \\ Tarleton State University \\ higham@tarleton.edu \\ Kimberly Rynearson \\ Professor \& Interim Dean \\ Tarleton State University \\ rynearson@tarleton.edu \\ Mark Weber \\ Associate Professor \\ Tarleton State University \\ weber@tarleton.edu \\ Tod Allen Farmer \\ Associate Professor \\ Tarleton State University \\ farmer@tarleton.edu \\ Randall Bowden \\ Professor \& Department Head \\ Tarleton State University \\ rbowden@tarleton.edu \\ Jesse Brock \\ Doctoral Fellow \\ Tarleton State University \\ sw_jbrock@tarleton.edu \\ Phillis Bunch \\ Doctoral Fellow \\ Tarleton State University \\ sw_bunch@tarleton.edu
}

\begin{abstract}
As members of the Carnegie Project on the Education Doctorate (CPED), universities across the United States are restructuring EdD programs to better prepare professional practitioners with the practical skills and theoretical knowledge needed to improve the educational environments that they serve. The hallmark of these programs is often the dissertation in practice, a scholarly investigation within which students define a problem of practice and then systematically test solutions to that problem. In this study, we investigate the experiences of university faculty participating in the redesign of an Educational Leadership EdD program who approach the redesign as a problem of practice. Root causes of identified program issues are presented in addition to the changes implemented in the redesigned program to improve upon the problem of practice.
\end{abstract}

Keywords: problem of practice; EdD program redesign; faculty

\section{INTRODUCTION}

Education doctorate programs have recently received renewed attention as institutions have worked to clearly differentiate EdD programs from PhD programs. The attention has likely stemmed in part from a provocative, scathing critique of professional preparation of educational practitioners by Shulman, Golde, Bueschel, and Garabedian (2006), in which the authors called for schools of education to clearly define the EdD or "risk becoming increasingly impotent in carrying out their primary mission - the advancement of
New articles in this journal are licensed under a Creative Commons Attribution 4.0 United States License.

This journal is published by the University Library System of the University of Pittsburgh as part of its D-Scribe Digital Publishing Program and is cosponsored by the University of Pittsburgh Press.

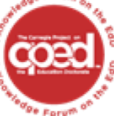

This journal is supported by the Carnegie Project on the Education Doctorate: A Knowledge Forum on the EdD (CPED) cpedinitiative.org
ISSN 2472-5889 (online) DOI 10.5195/ie.2020.100 
knowledge and the preparation of quality practitioners" (p. 25). EdD programs are intended to prepare individuals for administrative leadership positions in education (e.g., superintendents, curriculum coordinators, higher education administrators), whereas PhD programs are intended to prepare academic researchers and faculty members (Everson, 2006; Shulman, et al., 2006). With strikingly different purposes, the evolving historical similarity of $\mathrm{PhD}$ and $\mathrm{EdD}$ programs was perplexing with the EdD often simply defined "by subtraction" from the more weighty requirements of the $\mathrm{PhD}$ and often regarded as a "Ph.D.-Lite" (Shulman et al., 2006, p. 27).

\section{CARNEGIE PROJECT ON THE EDUCATION DOCTORATE}

In response to the call for reform, the Carnegie Project on the Education Doctorate (CPED) was launched in 2007 with the mission to work with institutions to transform EdD programs. Sponsored by the Carnegie Foundation for the Advancement of Teaching, CPED initially partnered with 25 member institutions. CPED has since partnered with over 100 institutions to redesign their EdD programs to prepare educational leaders who can "name, frame, and solve" (CPED, n.d., para. 9) educational problems (CPED, n.d.).

Rather than generate a strict redesign standard that would apply to all partner institutions, CPED honored the uniqueness of institutions' local contexts by advancing a framework that institutions could use as "building blocks" (Hoffman \& Perry, 2016, p. 17) to design components to achieve specific program aims. The framework was built around the definition of EdD - a degree that "prepares educators for the application of appropriate and specific practices, the generation of new knowledge, and for the stewardship of the profession" (CPED, n.d., para. 6). The framework's guiding principles and design concepts for program development put the definition into action by broadly conceptualizing what programs should do to prepare practitioners.

Central to EdD program design is the idea of the development of students as scholarly practitioners and stewards of the practice who can systematically identify and solve (or improve upon) educational problems in their local contexts (Perry, 2016a; Perry, 2016b). Programs seek to develop scholarly practitioners who can effectively bridge scholarship and practice - specifically in designing solutions to problems of practice through critical examination and application of findings from the literature (Archbald, 2008; Shulman et al. 2006; Willis, Inman, \& Valenti, 2010). CPED-influenced programs also honor the knowledge and skills that practitioners with established backgrounds in educational leadership bring to the process of identifying and solving problems of practice. Programs seek to further develop that practical wisdom in students to become stewards of the practice who generate new knowledge, conserve and preserve the evolution of the field to this point, and to transform the discipline based on new knowledge, skills, and dispositions (Golde, 2006; Perry, 2016b).

Programs often require evidence of the development of students as scholarly practitioners and stewards of the practice in several ways, with the most notable being the dissertation in practice. Like a traditional dissertation, a dissertation in practice is a scholarly investigation of an educational phenomenon; however, unlike a traditional dissertation for which theoretical issues are often studied, the dissertation in practice is one in which students are expected to identify problems of practice within their respective educational environments and then systematically test potential solutions to those problems (Storey, Caskey, Hesbol, Marshall, Maughan, \& Dolan, 2015). Through systematic investigations of problems of practice in the EdD coursework, CPED programs seek to build capacity in students to avoid the "adopt, attack, abandon cycle" (Rohanna, 2017, p. 65) common to educational administration, in which school leaders respond to issues through anecdotal understanding of the issue and responses based solely on practitioner knowledge and instinct. Instead, CPED-influenced programs seek to develop leaders who can effectively merge theory, research, and professional wisdom to solve particular problems of practice.

\section{TARLETON STATE UNIVERSITY EDD PROGRAM REDESIGN}

As new inductees into the Carnegie Project on the Education Doctorate consortium in 2017, a group of Educational Leadership doctoral program faculty at Tarleton State who also serve as the faculty authors on this paper, undertook a program redesign to better prepare practitioners to serve their particular educational constituencies. Prior to beginning the redesign process, it occurred to the faculty that we were undertaking the same type of actionoriented problem-solving process that we sought to facilitate with students; in other words, redesigning the Educational Leadership doctoral program became our problem of practice. We undertook the process of identifying the root causes of the problem of practice and facilitating solutions in the manner that we eventually expect students to work through their dissertations in practice in the redesigned program. By experiencing the process ourselves, the faculty aimed to be able to determine what would best facilitate the process with students and resolve any issues that arose before the redesigned program was officially implemented.

The purpose of this study was to document the initial stages of faculty's process of redesigning the program approaching it as a problem of practice. Although we intend to explicate the results of the redesigned program once implemented, this paper will focus on problem of practice identification and subsequent planning to improve upon the problem of practice. Although we have not yet implemented the redesigned program, we present results of our planning process to assist faculty who may undertake similar redesign processes and to add to the growing body of knowledge concerning the movement to create programs that differentiate the preparation of EdD students from $\mathrm{PhD}$ students. We present the results of our planning, however, fully anticipating that implementation will expose the need for changes and revisions. As such, we consider this a first iteration in what will be a continuously evolving program plan. We caution readers to approach the article with this in mind, considering that they may find more gratification in learning about the process we undertook rather than the initial product we created.

\section{Root Cause Analysis of Problem of Practice}

The process of problem of practice identification is not a simple task because it involves identifying root causes of a problem rather than superficially identifying symptoms that are most often more readily observable. Identifying root causes goes beyond surfacelevel assumptions via a deeper examination of the systemic reasoning behind an observed issue (Preuss, 2003). Consider, for example, an educational issue such as secondary students' 
difficulties in achieving objectives in Algebra I courses. On the surface, one might conclude that students' difficulties in passing Algebra I courses is the problem, but a deeper examination of why students exhibit difficulties passing Algebra I courses could uncover more systemic issues that contribute to students' difficulties with Algebra I, including but not limited to teachers' lack of preparation to teach Algebra I courses, curricular choices by districts or campuses that do not reflect best practice, and/or lack of financial resources to support students' investigations of mathematics. In this example, the surface-level assumption of the students' failures in Algebra I did not effectively represent the root causes that would likely need to be addressed to positively impact students' achievement in Algebra I courses. And, any improvements based on the limited understanding of the problem would not be expected to be as effective as improvements that were designed to address the root cause(s) of the problem.

The empirical methods familiar to most faculty are not designed to elicit root causes of problems; thus, we looked elsewhere for methods to investigate root causes of our problem of practice. We employed the root cause analysis method similar to processes used in business (Recker, Rosemann, Idulska, \& Green, 2009), engineering, manufacturing, and healthcare (see e.g., Joint Commission on Accreditation of Healthcare Organizations, 2017; Williams, 2001) to identify the underlying factors that may contribute to the issues identified within the program. The structure of the study did not follow the traditional study design expected with empirical methodologies, but rather an inductive root cause analysis informed by empirical data. The six-step process we used to investigate and identify the problem of practice is detailed in Figure 1, for which we first (a) identified the ideal condition of the program, then (b) identified the current condition, and (c) considered the gap between the two. The final steps involved (d) considering perspectives on the gap, (e) distilling root causes, and (f) identifying strategies for improvement (Preuss, 2003). Note that several of the steps naturally occurred together and will be presented accordingly in this paper.
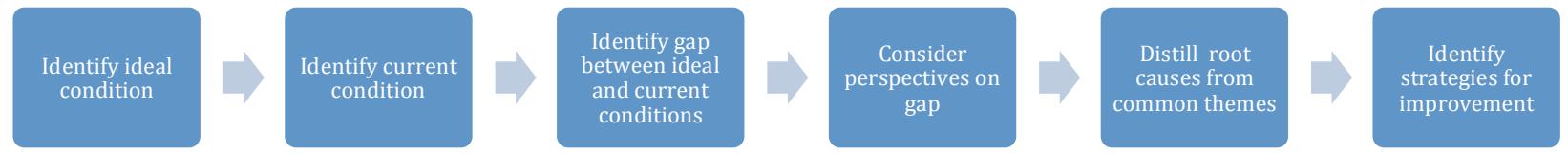

Figure 1. Root cause analysis process used to explicate the problem of practice. Process adapted from Preuss (2003).

\section{IDENTIFY IDEAL CONDITION}

Since it began in 2003, the Tarleton State University Educational Leadership EdD program has admitted cohorts of approximately 10-30 students across 2-3 campus locations each year. After anecdotally observing increasing times to degree completion and students' perceived lack of relevancy of the dissertation process to their work as educational leaders, faculty began discussing how to make the program more relevant and useful to students. We explored various sources and learned of the movement to reframe EdD programs led by the Carnegie Project on the Education Doctorate. We found that CPED's guiding principles and framework fit our purposes well, and we began to explore what that would look like for Tarleton State Educational Leadership doctoral students. After many discussions, we agreed upon the following mission and vision for the program, which summarizes our ideal state.

The program mission is to graduate learning leaders who use inquiry to improve professional practice with the goal of preparing educational leaders who use theory and practice to improve education by engaging multiple and diverse perspectives and building leadership capacity in themselves and others. Simply stated, we seek to grow leaders who can effectively use inquiry to improve practice in educational contexts. EdD graduates will become scholarly leaders who will navigate, critically respond to, and influence educational contexts by:

- Engaging in inquiry driven by theory, professional knowledge, and practice to transform educational organizations (related to CPED Guiding Principle 5, $6)$;
- Making evidence-based decisions that guide change and address problems of practice (related to CPED Guiding Principle 1, 4);

- Engaging in the assessment of educational outcomes as part of a continuous improvement process (related to CPED Guiding Principle 5);

- Understanding and advocating for change and social justice in educational settings (related to CPED Guiding Principle 1);

- Garnering resources to accomplish organizational goals and objectives to proactively impact education and the greater community (related to CPED Guiding Principle 3);

- Understanding and applying multiple leadership and organizational perspectives (related to CPED Guiding Principle 6);

- Understanding political climates and policy implications to inform actions for educational success (related to CPED Guiding Principle 2, 6); and

Collaborating and communicating with stakeholders to build partnerships with diverse communities (related to CPED Guiding Principle 2, 3).

\section{IDENTIFY CURRENT CONDITION, EXPLAIN GAP, AND CONSIDER PERSPECTIVES ON GAP}

We collected data from a total of 68 program stakeholders including faculty, students, and alumni to identify the current condition of the program in an effort to explain the gap between the current and ideal program. Data were collected from faculty $(N=8)$ via written interviews, and data were collected from students and alumni $(N=60)$ via an online, anonymous survey. 


\section{Faculty Participants}

All eight faculty participants were program faculty with interests in making program changes to better serve students' needs, and all served as coauthors on this paper. Note, however, that not all coauthors served as study participants.

The faculty's personal doctoral experiences were largely different than the EdD program in Educational Leadership in which they teach. Five (63\%) of the eight program faculty graduated with a doctoral degree in Educational Leadership or closely related field. The remaining three (38\%) faculty graduated with Doctor of Philosophy degrees in varied disciplines including Applied Technology and Performance Improvement, Educational Research, and Experimental Psychology. Differences in the preparation of faculty and the program that they are working to redesign are worthy of note; potential biases are acknowledged, but also seen as perspectives that could strengthen the identification of the gap between the ideal and current conditions and the program redesign in general. Only one $(13 \%$ of $N=8)$ of the faculty members completed a cohort-based program, and four $(50 \%$ of $N=8)$ of the eight participants indicated that dissertation work was largely an individual exercise.

Faculty were asked in a set of written interview questions to describe the current condition of the Tarleton State Educational Leadership EdD program by identifying strengths and limitations of the current program. Constant comparison was used to explore and categorize the responses into emergent themes using word processing and spreadsheet software. Rather than isolate themes by strengths and limitations, we integrated the two as would naturally occur when one considers aspects of program design. In all, faculty's perspectives comprised several themes including coursework, student-centered culture, faculty characteristics, and resource allocation.

Table 1. Faculty Participants' Gender and Doctoral Degree

\begin{tabular}{|l|l|l|l|l|}
\hline $\begin{array}{l}\text { Faculty } \\
\text { Member }\end{array}$ & Gender & Doctoral Degree & Program & $\begin{array}{l}\text { No. of years as a program } \\
\text { faculty }\end{array}$ \\
\hline A & Male & EdD & $\begin{array}{l}\text { Educational } \\
\text { Leadership }\end{array}$ & 1 \\
\hline B & Male & PhD & Higher Education & 10 \\
\hline C & Female & PhD & $\begin{array}{l}\text { Applied } \\
\text { Technology and } \\
\text { Performance } \\
\text { Improvement }\end{array}$ & 1 \\
\hline D & Male & PhD & $\begin{array}{l}\text { Foundations and } \\
\text { Leadership }\end{array}$ & 15 \\
\hline E & Female & PhD & $\begin{array}{l}\text { Experimental } \\
\text { Psychology }\end{array}$ & 3 \\
\hline F & Male & EdD & $\begin{array}{l}\text { Educational } \\
\text { Leadership }\end{array}$ & 3 \\
\hline G & Female & EdD & $\begin{array}{l}\text { Educational } \\
\text { Leadership }\end{array}$ & 2 \\
\hline H & Female & PhD & $\begin{array}{l}\text { Educational } \\
\text { Research }\end{array}$ & 6 \\
\hline
\end{tabular}

\section{Coursework}

Faculty cited particular aspects of the coursework as strengths and others as limitations. Three $(38 \%$ of $N=8)$ faculty mentioned the program curriculum emphasis on applying theory to practice, citing the "early historical and theoretical foundations in educational leadership...that subsequently assist/benefit professional practice" as a strength. Most faculty felt that the program has a "great balance of theory and practicality," although one faculty member commented that "pragmatism sometimes [gives] way to idealism." One faculty member commented that, "although the idea of theory to practice is explored within the program coursework, more ought to be done to help students explicitly link theory to practice to help encourage the systematic exploration of educational problems and the testing of solutions." The faculty member further commented that in the current coursework, "students are quick to jump to anecdotal diagnoses of 
educational problems and form knee-jerk solutions; we need to teach [students] how to use theory and literature to explore solutions that may be unfamiliar, but ultimately ones that may be more effective."

Also related to coursework, four ( $50 \%$ of $N=8)$ faculty commented that the course objectives are not purposefully connected, particularly to the dissertation expectations. One faculty member posited that the disconnect between course content and dissertation has in part contributed to negative results of program outcomes, such as increased students' times to degree completion.

Three $(38 \%$ of $n=8)$ faculty cited the role that the research preparation and mentorship (or lack thereof) played a role in students' readiness and abilities to complete the dissertation. One faculty member commented that, "many students seem to be surprised to be at the dissertation stage. They don't seem to possess the skills and knowledge to conduct sound independent research." The faculty member went on to suggest that students "might benefit [from changing the coursework to have students] conduct a small independent research study at a midpoint in their program."

At two points in the EdD program, students are required to travel on trips to supplement coursework experiences. Three (38\% of $N=8$ ) faculty cited the trips as strengths of the program. One faculty commented that the trips broaden students' perspectives through the opportunity to speak with K-20 practitioners in contexts outside of their own. Another faculty member referenced the required trips as interesting exercises, but ones that were not always directly connected to student or program objectives, with the implication that the issue may further the disconnect between course expectations and program outcomes.

Despite the program's limitations, five $(63 \%$ of $N=8)$ faculty credited the coursework for broadening students' perspectives and challenging them to think in new ways about the "prevailing questions surrounding their profession." However, one faculty member commented that the program is "dated" and needs to be updated to "apply to today's leaders," possibly indicating that the questions in the profession may not be the ones that are currently addressed.

\section{Resource Allocation}

Naturally, the program must have resources to operate, including but not limited to the human resources of faculty and support staff as well as financial resources to carry out program activities. Faculty participants noted that the "strong" and "experienced [and] caring" faculty are hampered in their abilities to interact with students in meaningful ways when asked to work on a limited budget and teach courses at three different locations. One faculty member commented that "spreading faculty among three distinct geographic region increases program delivery costs, limits faculty productivity due to travel, and negatively impacts faculty member's ability to become highly involved with any of the three locations and associated students." Another faculty member cited the increasing "faculty: student ratio and dissertation workload" as a concern related to resource allocation, particularly because as another faculty member pointed out, we "operate on a limited budget with an organizational culture that has had a historical focus on undergraduate education." The focus on undergraduate education has likely caused institutional administrators to think of the doctoral program similar to undergraduate education in terms of course numbers and loads. Similarly, a faculty member commented that we "exist in an environment of constant expected growth (number of students)... yet our faculty numbers remain static."

Limited resources also present a challenge as courses cannot always be taught by tenure-track faculty, and using adjuncts as instructors can lead to misalignment of the intended coursework and coursework delivery. One faculty member commented that the "inconsistent expectations for student work among the full-time faculty and adjunct faculty" was problematic and caused student complaints, with the rigor of adjunct-led courses sometimes lacking

\section{Student-centered culture}

The Tarleton State University vision as the "premier studentfocused university in Texas and beyond" (Tarleton State, n.d.) is, according to faculty, pervasive in the Educational Leadership Doctor of Education program. Faculty cited the "close student-faculty interactions" and "experienced caring faculty" that "care about students progressing through the program" as positive factors in the program design. One faculty member also mentioned the opportunity for students to "partner with faculty on scholarly endeavors" as a positive point of the program.

\section{Student Participants}

Although interesting and informative, faculty perspectives offer only one perspective on the current condition of the Educational Leadership EdD program, with students' perspectives potentially providing a more complete picture. We conducted a qualitative survey to examine students' attitudes toward the Tarleton State EdD in Educational Leadership program. Our goal was to identify students' perspectives of the current program and learn about ways the program could be improved through the CPED redesign process from a student perspective. To do so, we conducted an online survey using Qualtrics online survey software. All alumni and current students were invited to participate in the survey (283 participants invited). Overall, 60 alumni and current students responded to the survey resulting in a $21 \%$ response rate. See Table 2 for the sample's demographic information. Overall, the sample was relatively diverse in terms of student/alumnus status, gender, and age, but less so in terms of ethnicity with $58 \%$ of participants indicating their ethnicity as Caucasian. It should be noted, however, that students in the current program are primarily Caucasian, so results can be viewed as generally representative of the student population. 
Table 2. Demographic Characteristics of Student Sample $(N=60)$.

\begin{tabular}{|c|c|c|}
\hline & $\mathbf{n}$ & $\%$ \\
\hline \multicolumn{3}{|l|}{ Current student or alumnus } \\
\hline Current student & 29 & 48.3 \\
\hline Alumnus & 25 & 41.7 \\
\hline No response & 6 & 10.0 \\
\hline \multicolumn{3}{|l|}{ Gender } \\
\hline Female & 26 & 43.3 \\
\hline Male & 18 & 30.0 \\
\hline No response & 16 & 26.7 \\
\hline \multicolumn{3}{|l|}{ Age } \\
\hline $25-33$ years & 7 & 11.7 \\
\hline $35-44$ years & 15 & 25.0 \\
\hline 45-54 years & 20 & 33.3 \\
\hline $55-64$ years & 3 & 5.0 \\
\hline & 15 & 25.0 \\
\hline \multicolumn{3}{|l|}{ Race } \\
\hline Black or African-American & 8 & 13.3 \\
\hline White & 35 & 58.3 \\
\hline Other & 3 & 5.0 \\
\hline No response & 14 & 23.3 \\
\hline
\end{tabular}

The student survey featured questions about various topics pertaining to the Educational Leadership EdD program, such as inquiring about which factors made students choose to attend Tarleton State's EdD program, which courses were most meaningful to students in their roles as educational leaders, the out-of-course experiences (e.g., program-related trips), as well as soliciting suggestions to help improve the program in the future. Students responded to these questions by providing qualitative textual data. Data were analyzed for consistent themes similar to the analysis of faculty responses.

Several themes pertinent to the EdD program's current and desired future state were detected upon data analysis including the program's cohort-based model, hybrid course delivery model, course schedule, meaningful coursework, and out-of-course experiences. As part of the survey, students were also asked what suggestions they might have for future courses, topics, and out-of-course experiences to incorporate into the redesigned Educational Leadership program. Respondents offered several consistent themes as part of their feedback including more emphasis on higher education leadership and more exposure to research.

\section{Cohort-based model}

Thirty-seven ( $62 \%$ of $N=60)$ students consistently reported that the current program's cohort model was a positive aspect of the program. The cohort model helped students to develop professional and personal relationships with colleagues as well as to provide students with a peer support network. Peers also served as a source of accountability and helped motivate students to succeed in and complete the program.

\section{Hybrid course delivery model}

For the purpose of this study, the hybrid delivery model was defined as a course with both face-to-face and online components. Eighteen $(30 \%$ of $N=60)$ students indicated that they appreciated the 
hybrid course delivery model because it allowed for flexibility in scheduling for those with full-time jobs and/or families. Students stated that the online component of the classes was convenient in terms of scheduling and course access. However, the face-to-face component allowed for more personal interactions with professors and fellow students that are not achievable in an exclusively online environment. For example, one student reported:

\begin{abstract}
The hybrid delivery model provided by Tarleton State was ideal for my busy lifestyle. The Blackboard platform was easy to use and I could sign on anytime of day. The face to face portion of the program provided me the opportunity to interact with my cohort members and the professor. This combination of delivery method is one of the main reasons I was able to successfully complete this program. As a single parent, every minute counts!
\end{abstract}

\section{Night and weekend course schedule}

Thirty-five $(58 \%$ of $N=60)$ students reported that the night and weekend course schedule accommodated those who worked fulltime and had families. The response to this element of the current program was similar to the student response to the hybrid course model element.

\section{Out-of-course experiences}

The current program features two trips as part of out-of-course experiences. One is a trip to Washington, D.C., giving students an opportunity to see educational policy-making in action; the other is a trip to various school districts in southern Texas, exposing students to schools facing different issues and offering diverse perspectives regarding education practice. Students generally regarded these trips as highly informative experiences that stimulated good bonding experiences for the cohort members. One student noted:

The trip down south as part of our diversity institute was extremely beneficial!!! Being able to see inner city schools in Houston ISD and schools on the border (both urban and rural) provided perspective and insight that I would have never obtained without that trip. I draw from that experience regularly. It was a very enlightening trip that expanded my understanding of the struggles and successes of schools unlike those in which I have been associated. I learned more from that trip than any other experience in the program.

\section{Increased emphasis on higher education leadership}

Students were asked "What suggestions do you have for future course(s) or course topic(s) in the program?" In response to this inquiry, seven $(12 \%$ of $N=60)$ students indicated they would have appreciated more emphasis on higher education materials. In its current state, the EdD program attempts to balance K-12- and higher education-oriented materials. Through the program revision, it may be beneficial to focus more on topics more relevant to educational leaders in higher education.

\section{Increased exposure to qualitative and mixed- methods research}

Methodologically, the current EdD program is highly quantitatively focused, incorporating coursework on quantitative methodology and data analysis techniques, with relatively limited discussion of qualitative or mixed methods research. Because problem solving for educational leaders may involve leveraging and potentially mixing both quantitative and qualitative methods
(Archbald, 2014), the redesigned EdD program likely should incorporate a more balanced approach to discussing research methodology as suggested by two ( $3 \%$ of $n=60)$ of student participants.

\section{Incorporate dissertation into coursework throughout program}

In its current state, the Tarleton State University EdD program requires that students first complete all their coursework, and then, upon passing all their classes and qualifying examinations, they may work on their dissertations. As the CPED EdD model involves using the dissertation as a mechanism to examine a persistent problem of practice (The Carnegie Project on the Education Doctorate, n.d.), it may be beneficial to incorporate the dissertation process into earlier coursework so that students have the opportunity to more thoroughly study their respective problem of practice and therefore become better equipped to examine that problem as part of their dissertation.

\section{Exposure to more local legislation, practitioners, and perspectives}

As previously mentioned, the current program features several out-of-course experiences, including trips to Washington, D.C. and southern Texas. Although these trips expose students to a variety of perspectives in the field of education, several survey respondents indicated that exposure to more local practitioners and their perspectives, such as via travel to other local school districts, would yield greater insight into the issues educational leaders must face and address in a more local context. Furthermore, several students suggested that a trip to the Texas state capital in Austin would provide useful insight into the workings of state-level legislation. Overall, although student feedback suggested that out-of-classroom experiences were beneficial to their development as educational leaders, it may be prudent to modify the nature of these out-ofcourse experiences as part of the redesigned EdD program to better meet students' needs.

\section{Distill root causes from common themes and identify strategies for improvement}

The EdD redesign was initially spurred by undesirable program outcomes including students' increasing times to degree completion and a perceived lack of relevancy between coursework and the dissertation process to students' work as educational leaders. From our analysis of student and faculty perspectives on the current condition of the program and the gap between the current and ideal conditions, we have identified a set of root causes of the identified issues. Note that many of the root causes naturally mirror suggestions for improvement by faculty and students, and as a result have previously been discussed in detail. Rather than discuss the root causes again, in this section, we present the root causes alongside the strategies for improvement that were included in the redesigned program to improve upon the particular root cause. We also identify components from the current program that were viewed as strengths (i.e., not part of the problem of practice) that were subsequently retained in the redesigned program.

\section{Root Causes}

Several root causes were identified; they included the lack of connection of the dissertation to coursework, the restricted presentation of research methodologies, and limited emphasis on 
higher education coursework. To improve upon these issues, we considered three strategies for improvement: (a) explicitly connecting coursework with the dissertation process, (b) offering a balanced presentation of research methodologies, and (c) increasing the emphasis on higher education coursework. Improvement strategies based on the findings were incorporated into the redesigned program are discussed below.

\section{Connecting coursework with the dissertation}

To improve upon the perceived lack of connection between dissertation and coursework, the redesigned program will explicitly incorporate the dissertation process into coursework from the outset of the program instead of leaving it to the end as in the current program. The faculty identified milestones for dissertation progress that involve students explicating the root causes of the problem of practice by the end of Year 1, formally proposing the dissertation study by the end of Year 2, and defending the completed dissertation by the end of Year 3. The student would be guided in the dissertation study by faculty committees; in the first year, a Council of Chairs comprised of all potential dissertation chairs would review the students' dissertation progress and offer feedback, after which the student would work with a smaller committee of three to four faculty members to complete the dissertation in Years 2 and 3.

Coursework was selected to coincide with dissertation milestones to scaffold students through the process of completing the dissertation with the necessary knowledge and skills. For instance, students will consider the theory(ies) underlying their problem of practice while participating in the Models and Theories of Educational Leadership course and will consider data collection methods related to their identified problem of practice in the Investigating Problems of Practice in the Educational Leadership course. Courses were intentionally placed in a sequence to provide the necessary knowledge and skills related to dissertation completion to help students make consistent progress. And, with consistent progress, one can likely expect shortened times to degree and greater completion rates by students.

Faculty also chose to incorporate a scholar-practitioner based format for the dissertation as an option for students to increase the relevancy of the work to students' practice as educational leaders. The scholar-practitioner format option will comprise two productsone aimed at disseminating work to academic scholars and the other aimed at practitioners. The two products include: (a) a manuscript detailing the results of the dissertation study that would be suitable for publication in a scholarly journal and (b) an artifact suitable for practitioner audiences such as a white paper or presentation to a school board. Students will have the option to format the dissertation in five chapters if they so choose.

\section{Balanced presentation of research methodologies}

Given the varied nature of studies involving problems of practice (Archbald, 2014), faculty chose to educate students on a wider variety of research approaches than was presented in the current program. In the redesigned program, students will complete a five-course inquiry sequence ( 15 semester credit hours) that will integrate quantitative, qualitative, and mixed methodologies within each course. Students will begin their first semester (Year 1) with the Scholarly Process in Educational Leadership course that will teach them how to critically read academic literature and write in the same form; students will begin to conceive of possible problems of practice for their dissertation study in this course. The second inquiry course,
Research Design and Critical Analysis, will provide students a broad overview of quantitative, qualitative, and mixed research methodologies and introduce them to the concept of research ethics. The third course, Investigating Problems of Practice in Educational Leadership, will introduce students to data collection methods and challenge them to consider how they will investigate the root causes of their problems of practice. The final two courses in the inquiry sequence, Data Analysis and Advanced Data Analysis, will occur in Year 3 when data analysis skills are needed to complete the dissertation. The first of the two courses, Data Analysis, will provide students with introductory quantitative and qualitative analyses that they will use as a foundation to learn about advanced analyses needed to complete their dissertation work in Advanced Data Analysis.

Also included in program expectations will be yearly presentations of dissertation-related work by students at a practitioner research exchange. This out-of-course experience will be helpful in providing students with the accountability needed to make the expected progress in the identified timeline, but also for promoting students' work to internal and external audiences.

\section{Increased emphasis on higher education leadership}

Faculty elected to broaden the concentration options to two in the redesigned program-(a) Early Childhood $-12^{\text {th }}$ (EC-12) Education Leadership and (b) Higher Education Leadership to address the lack of emphasis on higher education noted by students and faculty. EC-12 and higher education students will take separate concentration courses (15 semester credit hours), but will progress through the core courses together. The combination of EC-12 and higher education students in the core courses will deepen students' understanding of key leadership competencies through the introduction of varied perspectives related to the issues based on the practical wisdom and experience that students bring to the program.

\section{Current Program Components Retained in Redesign Program}

In explicating the problem of practice, several components of the current program were identified as strengths that were retained in the redesigned program, although each was revised slightly to better meet students' needs. They included the cohort model, course delivery and scheduling, and out-of-course experiences. The components are detailed below.

\section{Cohort model}

The redesigned program will retain the cohort model of delivery that was identified by both students and faculty as a strength of the current program. Research also supports the positive impact that cohorts can have on students' success, including shortened times to degree completion and increased completion rates (Barnett \& Muse, 1993; Burnett, 1999; Dorn, Papalewis, \& Brown, 1995) as well as in developing stronger interpersonal relationships among students and faculty (Browne-Ferrigno \& Muth, 2003; Dorn, Papalewis, \& Brown, 1995). So that EC-12 and higher education students may benefit from the others' expertise in general education leadership principles, we elected to integrate the two groups of students in the core courses and break them out only for the courses particular to the concentrations; in other words, cohorts will comprise both students in the EC-12 and higher education concentrations. When students break out into concentration courses, however, they will have the 
opportunity to work with students in that same concentration from other cohorts, which will help to further their expertise in the identified concentration and broaden the students' network within their chosen concentration.

\section{Course delivery and scheduling}

The hybrid delivery of courses will be retained in the redesigned program as well as the scheduling of courses on nights and weekends. Online components offer the benefits of convenience with the face-to-face meetings helping to build and sustain relationships among students and faculty.

\section{Out-of-course experiences}

To increase students' perspectives of educational environments beyond their own, the redesigned program will retain the expectation that students will participate an out-of-course experience, but the number will be limited to one in the redesigned program and the students will be able to choose the experience that best meets their respective needs. Students will be expected to reflect and draw from those experiences within coursework and possibly the dissertation.

\section{CONCLUSION}

Faculty anticipate that the strategies employed to improve upon the identified root causes of program issues in combination with components retained from the current program will help achieve the mission of the redesigned program - to build "learning leaders who use inquiry to improve professional practice". It is through this sustained use of inquiry in the students' practice as educational leaders that we believe systemic, broad educational improvements can be achieved.

The exercise of approaching redesign as a problem of practice offered faculty critical knowledge concerning the gap between the ideal and current condition of the program as well as experience with the process of problem identification prior to facilitating the process with students. By approaching the program redesign as a problem of practice, as faculty, we sought to model the commitment to continuous improvement that we seek to build in students while also learning from the process ourselves.

\section{REFERENCES}

Archbald, D. (2008). Research versus problem solving for the education leadership doctoral thesis: Implications for form and function. Educational Administration Quarterly, 5(44), 704-739.

Archbald, D. (2014). The GAPPSI Method: Problem-solving, planning, and communicating - concepts and strategies for leadership in education. Ypsilanti, MI: NCPEA Publications.

Barnett, B. G., \& Muse, I. D. (1993). Cohort groups in education administration: Promises and challenges. Journal of School Leadership, 3, 400-415.

Browne-Ferrigno, T., \& Muth, R. (2003). Effects of cohorts on learners. Journal of School Leadership, 13(6), 621-643.

Burnett, P. C. (1999). The supervision of doctoral dissertations using a collaborative cohort model. Counselor Education and Supervision, 39 , 46-52.

Carnegie Project on the Education Doctorate (n.d.). About Us. Retrieved from http://www.cpedinitiative.org/page/AboutUs

Dorn, S. M., Papalewis, R., \& Brown, R. (1995). Educators earning their doctorates: Doctoral student perceptions regarding cohesiveness and persistence. Education, 116, 305-314.
Everson, S. T. (2006). The role of partnerships in the professional doctorate in education: A program application in educational leadership. Educational Considerations, 33(2), 1-15.

Golde, C. M. (2006). Preparing stewards of the discipline. In C. M. Golde, \& G E. Walker (Eds.), Envisioning the future of doctoral education (pp. 3-23). San Francisco, CA: Jossey-Bass.

Hoffman, R. L., \& Perry, J. A. (2016). In J. A. Perry (Ed.), The EdD and the scholarly practitioner: The CPED path (pp. 13 - 25). Charlotte, NC: Information Age Publishing.

Joint Commission on Accreditation of Healthcare Organizations (6th ed.) (2017). Root cause analysis in health care: Tools and techniques. Oakbrook Terrace, IL: Author.

Perry, J. A. (2016a). The scholarly practitioner as steward of the practice. In Storey, V. A., and Hesbol, K. A. (Eds.), Contemporary approaches to dissertation development and research methods ( $1^{\text {st }}$ ed., pp. 300-313). New York, NY: Information Science Reference.

Perry, J. A. (2016b). The new education doctorate: Preparing the transformational leader. In J. A. Perry (Ed.), The EdD and the scholarly practitioner: The CPED path (pp. 1 - 10). Charlotte, NC: Information Age Publishing

Preuss, P. G. (2003). School leaders' guide to root cause analysis: Using data to dissolve problems. Larchmont, NY: Eye on Education.

Recker, J., Rosemann, M., Indulska, M., \& Green, P. (2009). Business process modeling - A comparative analysis. Journal of the Association for Information Systems, 10(4), 333-363.

Rohanna, K. (2017). Breaking the "adopt, attack, abandon" cycle: A case for improvement science in K-12 education. In C. A. Christie, M. Inkelas \& S. Lemire (Eds.), Improvement Science in Evaluation: Methods and Uses. New Directions for Evaluation, (153), 65-77.

Shulman, L. S., Golde, C. M., Bueschel, A. C., \& Garabedian, K. J. (2006). Reclaiming education's doctorates: A critique and a proposal. Educational Researcher, 35, 25-32.

Storey, V. A., Caskey, M. M., Hesbol, K. A Marshall, J. E., Maughan, B., \& Dolan, A. W. (2015). Examining EdD dissertations in practice: The Carnegie Project on the Education Doctorate. International HETL Review, 5(2). Retrieved from https://www.hetl.org/examining-edddissertations-in-practice-the-carnegie-project-on-the-educationdoctorate/

Tarleton State University (n.d.). Mission/Vision/Core Values. Retrieved from https://www.tarleton.edu/strategicplan/2016-2020/mission-vision.html

Williams, P.M. (2001). Techniques for root cause analysis. Baylor University Medical Center Proceedings, 14(2), 154-157.

Willis, J., Inman, D., \& Valenti, R. (2010). Completing a professional practice dissertation: A guide for doctoral students and faculty. Charlotte, NC: nformation Age Publishing. 